\title{
Arthroscopic autologous chondrocyte implantation in the hip for the treatment of full-thickness cartilage defects
}

\section{A case series of 29 patients and review of the literature}

\author{
Steffen Thier ${ }^{1,4, *}$, Christel Weiss ${ }^{2}$, and Stefan Fickert ${ }^{3,4}$ \\ 1 Sportchirurgie Heidelberg, ATOS Clinic Heidelberg, 69115 Heidelberg, Germany \\ 2 Institute of Biostatistics, University Medical Centre Mannheim, Medical Faculty Mannheim, University of Heidelberg, \\ 68167 Mannheim, Germany \\ 3 Sporthopaedicum Straubing Berlin Regensburg, 94315 Straubing, Germany \\ 4 University Medical Centre Mannheim, Medical Faculty Mannheim, University of Heidelberg, 68167 Mannheim, Germany
}

Received 2 January 2017, Accepted 30 May 2017, Published online 19 December 2017

\begin{abstract}
Purpose: Current literature indicates that the appropriate treatment of articular cartilage defects has significant influence on the postoperative outcome after hip arthroscopy. In the hip, arthroscopic treatment of cartilage defects is technically challenging, especially the autologous chondrocyte implantation/matrix-associated autologous chondrocyte implantation (ACI/MACI) procedures. The purpose of this prospective study was to introduce two injectable MACI products with self-adherent properties. Furthermore, we report short-term outcome and review the current literature.

Methods: Full-thickness cartilage defects of 29 patients caused by the femoroacetabular impingement (FAI) were treated arthroscopically with an injectable MACI product in a two-step surgical procedure. The patient-related outcome was assessed with International Hip Outcome Tool (iHOT33), Euro-Quol group score (EQ-5D) and NonArthritic-Hip-Score (NAHS) at baseline, six weeks, six, 12 and 24 months.

Results: Twenty-nine out of 46 patients (27 male/two female) with a mean age of 30.3 years (range $18-45$ years) and an average defect size of $2.21 \mathrm{~cm}^{2}$ were available for follow-up after a mean of 19 months (range 6-24 months). All defects were located on the acetabulum International Cartilage Repair Society (ICRS) grade 3A-3D (nine 3A; eleven 3B; six 3C; three 3D). Twenty-six patients had associated labral pathology (23 repair 1-5 anchors; three partial trimming). Twenty-seven defects were caused by the FAI (20 CAM, six combined, one Pincer), two cases were of traumatic cause. An overall statistically significant improvement was observed for all assessment scores at an average follow-up of 19 months.

Conclusion: In this study, we present short-term data of new arthroscopic injectable matrix-associated, autologous chondrocyte implants as a treatment option for full-thickness cartilage defects of the hip. All patient-administered assessment scores demonstrated an increase in activity level, quality of life and reduction of pain after a 19-month follow-up. Further randomized controlled trails (RCTs) with comparison of natural history, bone marrow stimulation techniques and MACI of the hip have to approve the results in long-term follow-up.
\end{abstract}

Key words: Hip arthroscopy, Autologous chondrocyte implantation, ACI, Cartilage defect, Matrix-associated autologous chondrocyte implantation, MACI.

\section{Introduction}

The femoroacetabular impingement (FAI) is one of the main causes of hip cartilage defects that may subsequently lead to the development of hip osteoarthritis. The CAM-type FAI is particularly associated with large acetabular cartilage defects [1].
As in the current literature there seems to be a correlation between the stage of cartilage loss and postoperative outcome, the appropriate treatment of articular cartilage defects has significant influence on the postoperative outcome [2-5].

Articular cartilage is a tissue with unique capacity of load distribution and low-friction articulating surfaces [6]. Despite

\footnotetext{
*Corresponding author: steffen.thier@atos.de
} 
approximately four million load cycles a year with peak loads around $18 \mathrm{MPa}$, the articular cartilage is able to maintain its biomechanical function over decades [7]. Unfortunately in adults, the low metabolic and proliferative activity of articular cartilage results in a limited intrinsic capacity of self-repair [8].

Several surgical techniques, such as marrow stimulation techniques, osteochondral transplantation, autologous matrix-induced chondrogenesis (AMIC) and autologous chondrocyte implantation (ACI), have been made to restore articular surfaces. These techniques are routinely used in the knee. In the hip however, arthroscopic treatment of cartilage defects is technically challenging, mainly because of the restricted space in the central compartment. Consequently, most studies of the current literature report data on the microfracture procedure. These studies are mostly case series without control groups and rather small patient numbers classified as evidence-based medicine (EBM) levels III-IV $[2,3,9-13]$.

In contrast to the knee joint, only limited data has been published on arthroscopic or open autologous chondrocyte transplantation in the hip [14-17]. The main reasons for the limited use of ACI procedures on the hip are the restricted space during arthroscopy due to osseous and labral containment and the technically demanding procedure [14]. Additionally, there are high demands on the ACI-System, which should be capable of a purely arthroscopic implantation without further fixation with sutures, adhesives or resolvable nails [14-16]. The development of third generation ACI, so-called matrixassociated chondrocyte implantation, combines self-adhesive properties with purely arthroscopic implantation [18-20].

The purpose of this case series is to report short-term data of two different injectable matrix-associated autologous chondrocyte implantation (MACI) products for the arthroscopic treatment of cartilage defects of the hip joint. The postoperative outcome is measured by using established scoring systems (International hip outcome tool (iHOT33), Non-arthritic-hip-score (NAHS), Euro-Quol group score (EQ-5D)). The results of these products are evaluated on the basis of the present reviewed literature.

\section{Materials and methods}

This prospective case series was carried out according to the principles of the Declaration of Helsinki. We report early clinical data of 46 patients with isolated acetabular cartilage defects treated with an arthroscopic, matrix-associated autologous chondrocyte implantation (MACI) in a two-step procedure.

The preoperative patient assessment consisted of a clinical examination and standardized conventional X-rays. Anteriorposterior and cross-table radiographs [21] were performed and evaluated for signs of FAI and osteoarthritis.

Furthermore, all patients underwent magnetic resonance arthrography (MRA) with additional radial reconstruction for the detection of chondral and labral damage. Solely patients with suspicion of an acetabular cartilage defect in the MRA were eligible for inclusion [22].
After inclusion and exclusion criteria were verified and the patient provided informed consent, hip arthroscopy was performed. If a cartilage defect grade $3 \mathrm{~A}-4$ according to the International Cartilage Repair Society (ICRS) score were detected, the cartilage was harvested and blood samples were taken for the cultivation process.

Our hospital is authorized for the withdrawal, donation and procurement of human tissues and cells in accordance with the Directive 2004/23/EC. The study was approved by the Local Ethics Committee.

\section{Inclusion criteria}

Twenty-nine patients (27 male/two female) fulfilled the inclusion criteria with an age between 18 and 50 years. Patients with an acetabular full-thickness cartilage defect scored $3 \mathrm{~A}-4$ according to ICRS and a minimum follow-up of six months were included.

\section{Exclusion criteria}

Patients with non-contained acetabular cartilage defects, damage to the subchondral bone lamella in the defect, multiple defects or kissing lesions (opposing defects) were excluded. Furthermore, all patients with a Kellgren and Lawrence score for osteoarthritis $>2$ and signs of dysplasia were excluded.

\section{Outcome evaluation}

Baseline evaluation was done before index hip arthroscopy. Further outcome evaluations were performed at six weeks, three, six, 12 and 24 months after ACI utilizing three validated scores: EQ-5D, (general health/mental and physical); iHOT33 (pain, hip-specific function, daily living and sports); NAHS (sport activities, function) [23-25].

\section{Aim of study}

The aim of the study was to compare the subjective patient outcome at 19 months after ACI of the hip with the baseline evaluation before arthroscopy by utilizing the NAHS, iHOT 33 and EQ-5D.

\section{Operation technique and treatment with NOVOCART ${ }^{\circledR}$ Inject and Chondrosphere ${ }^{\circledR}$}

Hip arthroscopy was performed with the patient placed in the supine position. Approximately $10-15 \mathrm{~mm}$ joint distraction was used. To access the central compartment the anterolateral and anterior portal were established. Subsequently, the hip joint was investigated for labral and chondral damage. After appropriate classification of the cartilage defect according to ICRS, the indication for treatment with ACI was verified. Treatment of coexisting pathologies was performed during index arthroscopy (e.g., labral repair, offset reconstruction). 




Figure 1. Adjustment of the application needle after debridement of a full-size cartilage defect at the anterolateral acetabulum.

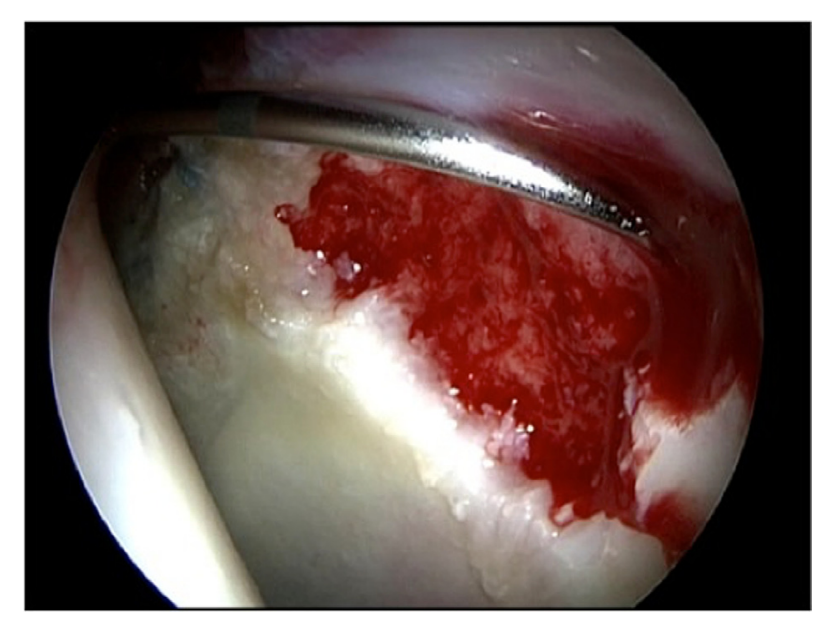

Figure 2. Application of NOVOCART ${ }^{\circledR}$ Inject.

As many as 2-3 full-depth cartilage cylinders were harvested from the head-neck junction during first arthroscopy.

In cases of $\mathrm{NOVOCART}^{\circledR}$ Inject, the cartilage specimens and $10 \mathrm{~mL}$ autologous patient serum were sent to the manufacturer. Patient's chondrocytes were isolated from the cylinders and expanded as a primary culture in vitro in a Good Manufacturing Practice (GMP) approved facility (TETEC AG, Reutlingen, Germany) [18, 20].

In cases of Chondrosphere ${ }^{\circledR}$, the cartilage specimens and $200 \mathrm{~mL}$ autologous patient serum were added to co.don (Fa. co. don AG, Teltow, Germany) for further isolation and culturing of three-dimensional spheroids as previously described [26].

In the second procedure, the defect was debrided arthroscopically to produce stable perpendicular margins (Figure 1). An additional posterolateral portal was established to drain intraarticular fluid. Fluid irrigation was then stopped to achieve dry conditions in the joint. Depending on the angulation, MACI was implanted through the anterior or anterolateral portal.

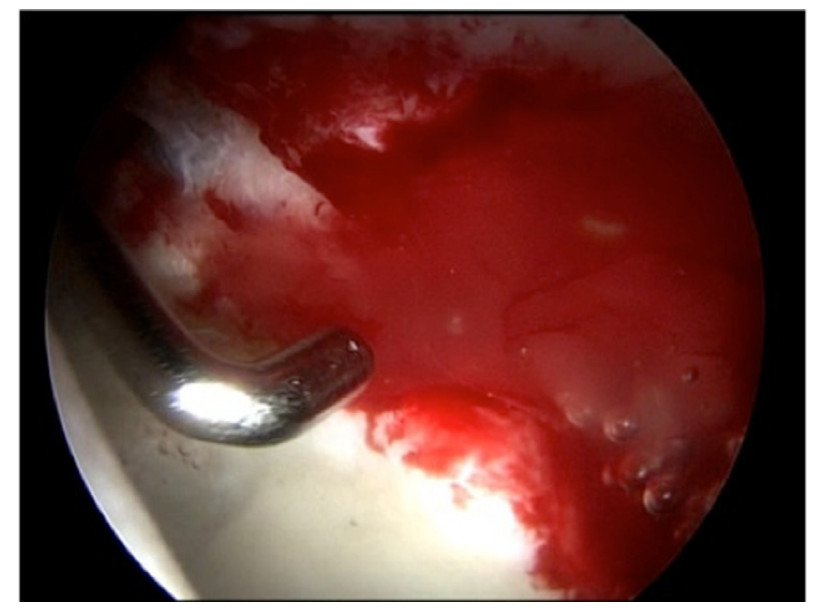

Figure 3. Testing the stability of matrix-associated autologous chondrocyte implant (MACI) with a hook after application and fluid irrigation.

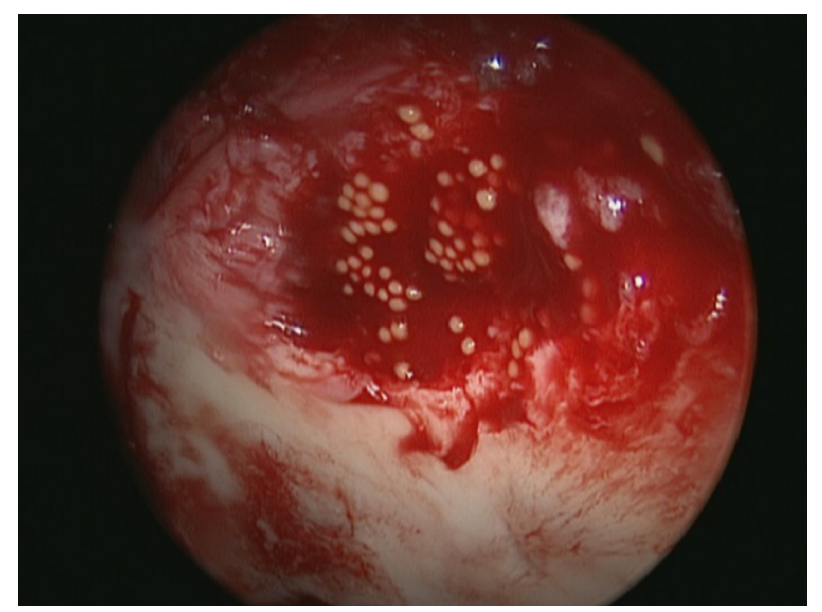

Figure 4. Application of Chondrosphere ${ }^{\circledR}$.

The chondral defect was carefully covered with NOVOCART $^{\circledR}$ Inject, a combination of autologous cartilage cells and an in situ polymerizable hydrogel, through the deformable applicator (Figure 2). The injectable hydrogel, a combination of human albumin and hyaluronic acid, together with the autologous chondrocytes polymerizes in $30-60 \mathrm{~s}$ and bonds immediately to the bottom of the defect (Figure 3).

The Chondrosphere ${ }^{\circledR}$ implantation is performed in a similar fashion. A deformable applicator, which can be adjusted in length and angle, is used for the dropwise implantation of the spheroids in the defect (Figure 4). Immediately after the introduction of the spheroids their distribution can be adapted with a hook.

The spheroids bond after approximately $20 \mathrm{~min}$ is macroscopically visible when the spheroids change their form from round to flat.

Due to the adhesive properties of the MACI-Systems no further fixation is needed. 


\section{Rehabilitation}

After index surgery, patients with labral repair were restricted to $80^{\circ}$ flexion for six weeks. The rehabilitation protocol after ACI consisted of continuous passive motion (CPM) therapy for four weeks (minimum three hours a day) and $20 \mathrm{~kg}$ partial weight bearing for six weeks postoperatively. Physiotherapy was allowed in pain-free range of motion. Low impact sport was administered at three months and high impact sport at six months postoperatively.

Clinical and outcome evaluation were performed at six weeks, three, six, 12 and 24 months after ACI. Additionally, data concerning pain medication, tolerability of the ACI and adverse events were collected.

\section{Statistical analysis}

All statistical calculations have been done using SAS software, release 9.3 (SAS Institute Inc., Cary, NC, USA). For qualitative factors, absolute and relative frequencies are given. Quantitative variables are presented by mean \pm standard deviation. In order to investigate changes over time, an analysis of variance (ANOVA) for repeated measurements has been performed for each quantitative outcome using the SAS procedure SAS MIXED (with patients' ID as a random factor). Dunnett's test has been applied in order to enable comparisons to baseline. Mean values between two groups (i.e., MACT (maximum achievable control technology) product) have been compared with two-sample $t$-tests. Furthermore, Pearson correlation coefficients have been assessed in order to quantify the strength of correlation between two quantitative parameters (i.e., between an outcome variable and cartilage defect size or size of labrum tear). A statistical test result has been considered as statistically significant for $p<0.05$.

\section{Results}

\section{Baseline characteristics}

A total of 29 patients ( $27 \mathrm{men} / \mathrm{two}$ women) aged between 18 and 45 years (mean age 30.3 years) were included in this investigation. The average time of follow-up was 19 months (range 6-24 months). All patients were diagnosed with a full-thickness chondral defect of the acetabulum grade 3A-3D (nine 3A; eleven 3B; six 3C; three 3D) according to ICRS classification. Five patients showed radiographic osteoarthritis grade $2^{\circ}$, six grade $1^{\circ}$ and 18 patients showed no signs of osteoarthritis.

All defects were located on the acetabulum between 12 and 5 o'clock position. The mean defect size was $2.21 \mathrm{~cm}^{2}$, no concomitant cartilage defect was seen. Twenty defects were caused by CAM-type FAI, six by combined FAI, one by Pincer-type FAI and two were of traumatic cause. No previous operation was performed on the same hip.

During index arthroscopy, 28 patients received additional treatment on the affected hip: offset reconstruction was performed on all 28 patients, of which 12 patients received additional acetabuloplasty.
Table 1. Demographic data and baseline centeracteristics of the study population.

\begin{tabular}{lcc}
\hline Demographics & & $(\%)$ \\
\hline Age in years & $30.3 \pm 6.9$ & $(18-45)$ range \\
Gender (male/female) & $27 / 2$ & $(93 / 7)$ \\
Locality/grade of defect & & \\
$\quad$ Acetabular & 29 & $(100)$ \\
3A & 9 & $(31)$ \\
3B & 11 & $(38)$ \\
3C & 6 & $(21)$ \\
3D & 3 & $(10)$ \\
Grade of osteoarthritis & 18 & \\
$0^{\circ}$ & 6 & $(62)$ \\
$1^{\circ}$ & 5 & $(12)$ \\
$2^{\circ}$ & & \\
Type of FAI & 20 & $(69)$ \\
CAM & 1 & $(3)$ \\
Pincer & 6 & $(21)$ \\
Combined & 2 & $(7)$ \\
Trauma & 29 & \\
Total number of hips & & \\
\hline
\end{tabular}

Twenty-six patients had labral pathology of which 23 received labral repair with one to five anchors and three partial trimming of the labrum. The extension of the labral defects on a clock rating varied from 1 to 5 o'clock. The demographic data and baseline characteristics of the study population are illustrated in Table 1.

\section{Functional outcome evaluation}

The clinical efficacy of the MACI-System was evaluated with three validated outcome scales such as iHOT33, NAHS and Short-Form Health Survey. Each scale displayed a significant improvement $(p<0.05)$ at a mean of 16 months after ACI in comparison to baseline. The detailed illustration for each score is demonstrated in the following.

\section{International hip outcome tool (iHOT33)}

All patients treated with ACI showed an overall improvement at 24 months according to the iHOT33 in comparison to baseline $(p=0.0002)$ (mean score at baseline: $48.9 \pm$ $17.1 \%$; 12 months after MACI: $70.1 \pm 20.3 \%$ (19 patients); 24 months after MACT: $67.2 \pm 23.2 \%$ (19 patients)).

At three months significant improvement was seen $(p=0.0007)$. There was further improvement at six months $(p<0.0001)$ and 12 months $(p<0.0001)$ after surgery.

\section{Non-arthritic-hip-score (NAHS)}

Patients improved significantly in the Non-Arthritic-HipScore after the treatment with ACI compared to baseline at 24 months $(p=0.0009)$ (mean score at baseline: $66.6 \pm 14.4 \%$; 12 months after MACI: $79.4 \pm 16.4 \%$ (19 patients); 24 months after MACT: $80.1 \pm 11.6 \%$ (19 patients)). Significant improvement was monitored at six months $(p=0.0004)$ and 12 months $(p=0.0014)$ after surgery. 


\section{Euro-Quol group score (EQ-5D)}

Patients who underwent ACI of the hip showed an overall improvement according to EQ-5D when compared with baseline data (mean score at baseline: $58.7 \pm 16.6 ; 12$ months after MACT: $78.1 \pm 16.8$ (19 patients); 24 months after MACI: $73.1 \pm 20.3)$. The improvements compared to baseline were significant (three months: $p=0.0003$, six months: $p=$ 0.0002; 12 months: $p<0.0001$; 24 months: $p=0.0024$ ).

All outcome evaluations are displayed in Figure 4.

\section{Subgroup analyses}

Three variables were categorized (cartilage defect size, labral defect size and MACI product) and analysed in regard to their potential influence on the outcome following arthroscopic MACI of the hip (Figure 5).

\section{Cartilage and labral defect size}

Overall no relevant influence could be detected regarding the size of the cartilage defect and the size of the labral tear on the functional outcome in the iHOT33, EQ-5D and NAHS at 12 months and at 24 months $(p>0.05)$. All correlation coefficients have absolute values and are less than 0.3 due to the small number of patients. Therefore, no statistically relevant conclusions can be drawn.

\section{$\mathrm{MACl}$ product}

The postoperative outcome results at 12 months (iHOT33 $p=0.4839$; EQ-5D $p=0.6427$; NAHS $p=0.2850)$ and 24 months (iHOT33 $p=0.4684$; EQ-5D $p=0.4643$; NAHS $p=0.4595)$ did not show a significant difference between the two MACI products using $t$-tests. Descriptive data of both products are illustrated in Table 2.

\section{Discussion}

The aim of the present study was to report short-term results of 29 patients treated with ACI of the hip and a review of the current literature.

Two different MACI products were used, both can be transplanted arthroscopically (NOVOCART ${ }^{\circledR}$ Inject/ Chondrosphere $^{\circledR}$ ). The results were evaluated with respect to mental and physical health, pain and functionality in patients with isolated cartilage defects caused by FAI. In 19 cases, we were using NOVOCART ${ }^{\circledR}$ Inject and Chondrosphere ${ }^{\circledR}$ in 10 cases. Overall, the final scores after treatment with both products revealed statistically significant increased levels of activity and quality of life after an average follow-up of 16 months. However, we could not monitor significant differences between both products in the outcome scores. This indicates that in terms of pain relief and improvement of hip function the NOVOCART ${ }^{\circledR}$ Inject (Figure 6) and Chondrosphere ${ }^{\circledR}$ (Figure 7) seem to be effective treatment methods for fullthickness cartilage defects of the hip.

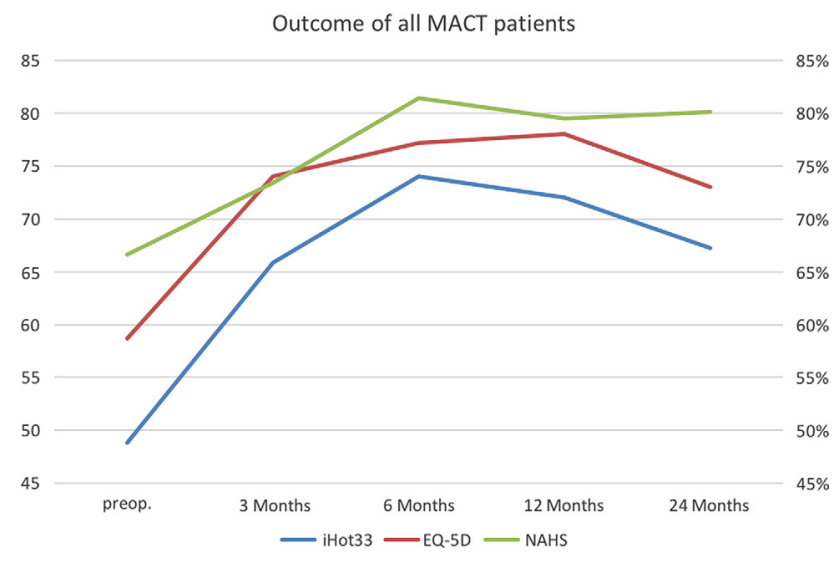

Figure 5. Outcome evaluation of all patients after MACI of the hip.

The current literature indicates a correlation of cartilage defects and the degree of cartilage damage with inferior outcome results in FAI patients. In this context, Haviv et al. showed at a follow-up of 22 months that limited cartilage injury resulted in a better outcome in contrast to severe cartilage injury [3]. McCarthy et al. concluded that patients with the combination of severe cartilage injury (Outerbridge III $^{\circ}$ and $\mathrm{IV}^{\circ}$ ) and higher age have the highest risk for treatment failure "conversion to THA" [27]. Philippon et al. reported a correlation of the status of cartilage damage with the subjective outcome. At 2.3 years follow-up, cartilage status classified as mild, moderate and poor had modified Harris Hip Scores (mHHS) of 87, 79 and 62, respectively [4]. Several authors concluded that in cases of labral tears a coexisting cartilage defect seems to lead to significantly poorer outcome results $[2,5,28]$. These studies show that cartilage defects have the most direct impact on the postoperative outcome after hip arthroscopy. This indicates the importance of the appropriate treatment of cartilage defects of the hip.

In the hip, as a deep ball-and-socket joint is surrounded by a large number of muscles, access to the joint is difficult. The treatment of the central compartment is especially challenging, as joint distraction should be restricted to $10-15 \mathrm{~mm}$ and distraction times should be limited during arthroscopy to avoid complications [29]. The localization of cartilage defects of FAI patients, in the majority in the anterolateral position of the acetabulum, challenges cartilage repair systems to dispense with further fixation by suture or adhesives [15]. Accordingly, a self-adherent ACI-System whose applicator can easily be passed through an arthroscopic cannula and enables uniform distribution of chondrocytes in the defect area by a special vortexer seems to be the ideal solution for the hip joint [14].

To our knowledge, this is the first study reporting data about NOVOCART ${ }^{\circledR}$ Inject for the treatment of cartilage defects in the hip. Preclinical research has proven positive biologic effects and biocompatibility of the components of NOVOCART $^{\circledR}$ Inject [18]. The transplant is characterized by stabilization of the chondrocyte phenotype [30] and the hydrogel has shown anti-angiogenic and anti-osteogenic effects that inhibit inflammation $[19,31]$. 
Table 2. Descriptive data on the two MACI products.

\begin{tabular}{|c|c|c|c|c|c|c|c|c|c|c|c|c|}
\hline Product & Variable & $N$ & $M$ & $S D$ & Min & Max & Variable & $N$ & $M$ & $S D$ & Min & $\overline{\operatorname{Max}}$ \\
\hline \multirow[t]{3}{*}{ Novocart } & iHOT33 12 months & 10 & 74.2 & 16.6 & 43.0 & 97.0 & iHOT33 24 months & 11 & 69.2 & 21.8 & 34.0 & 98.0 \\
\hline & EQ_5D 12 months & 10 & 79.7 & 13.8 & 50.0 & 95.0 & EQ_5D 24 months & 11 & 76.1 & 15.4 & 40.0 & 95.0 \\
\hline & NAHS 12 months & 10 & 84.0 & 10.8 & 62.5 & 100 & NAHS 24 months & 11 & 81.4 & 11.9 & 61.3 & 98.8 \\
\hline \multirow[t]{3}{*}{ Codon } & iHOT33 12 months & 9 & 69.7 & 24.5 & 17.0 & 96.0 & iHOT33 24 months & 8 & 64.4 & 26.3 & 24.0 & 96.0 \\
\hline & EQ_5D 12 months & 9 & 76.2 & 20.3 & 30.0 & 97.0 & EQ_5D 24 months & 8 & 68.9 & 26.3 & 35.0 & 97.0 \\
\hline & NAHS 12 months & 9 & 74.4 & 20.6 & 23.7 & 88.8 & NAHS 24 months & 8 & 78.0 & 11.7 & 63.8 & 96.3 \\
\hline
\end{tabular}

Outcome patients Novocart Inject

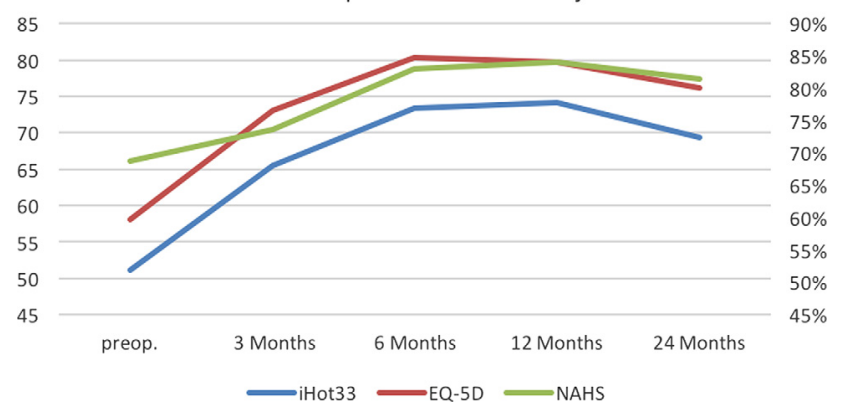

Figure 6. Outcome NOVOCART ${ }^{\circledR}$ Inject.

The Chondrosphere ${ }^{\circledR}$, an autologous MACI product, which can also be transplanted arthroscopically, has already been used in the hip joint [14]. This technique offers growth and phenotypic stability, while consisting of human autologous spheroids in $0.9 \% \mathrm{NaCl}$ suspension. The spheroids derive from human autologous chondrocytes, which can produce cartilage-specific matrix and are able to build a three-dimensional structure under defined cell culture conditions [14, 26].

However, a possible advantage of NOVOCART ${ }^{\circledR}$ Inject may be the remarkable bonding capacity of the in situ polymerizable hydrogel. A comparison of both products is illustrated in Table 3.

Until now, three studies have displayed the feasibility and reported short-term data of Chondrosphere ${ }^{\circledR}$ for use in the hip joint. Fickert et al. reported significant improvement in the outcome scores (mHHS and NAHS) in six patients with an average cartilage defect size of $3.5 \mathrm{~cm}^{2}$ at 11 months follow-up [14]. Körsmeier et al. included 16 patients with cartilage defects of $4.52 \mathrm{~cm}^{2}$ in their study. They monitored a significant improvement in the outcome scores at 16 months displayed in the Western Ontario and McMaster Universities Osteoarthritis Index (WOMAC) score and NAHS [16]. Schroeder et al. reported significant improvement in the iHOT33, mHHS and subjective hip value (SHV) scores in 20 patients with an average defect size of $5.05 \mathrm{~cm}^{2}$ at 12 months follow-up [17].

Fontana et al. in contrast used a polymer-based scaffold (BioSeed $^{\circledR}-\mathrm{C}$, BioTissue Technologies GmbH) [15, 32], which was seeded with the expanded chondrocytes after cultivation. Thus it is not a classical MACI product, where scaffolds have to be seeded prior to cultivation. From the technical point of

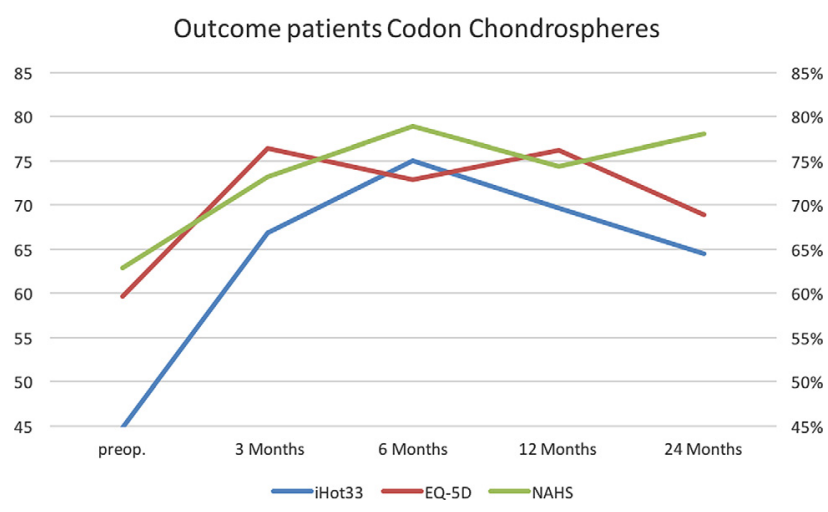

Figure 7. Outcome Chondrosphere ${ }^{\circledR}$.

view, their rigid scaffold needed to be cut in approximate shape before introducing the folded scaffold through the cannula in the joint. Apart from the difficult handling, the scaffold is lacking in self-bonding capacity and as a result only acetabular defects could be treated arthroscopically without further fixation $[15,33]$.

However, Fontana et al. reported five-year follow-up results of 15 patients with chondral defects of the hip treated with ACI in comparison to a group with simple debridement in a retrospective study design. After 5 years, the ACI group showed a significant better outcome in the Harris Hip Score (HHS) compared to the debridement group [15].

In a second study, the same author compared 26 patients treated with ACI with 31 patients treated with an AMIC procedure (Chondro-Gide ${ }^{\circledR}$, Geistlich Pharma AG, Switzerland). Both groups showed similar significant improvement in the mHHS at five-year follow-up in cartilage defects of $2.8 \mathrm{~cm}^{2}$ in the ACT-group and $2.9 \mathrm{~cm}^{2}$ in the AMIC-group [33]. However, both study results should be interpreted with care due to a possible selection bias as their control groups had been selected out of 144 patients.

Similar to this study, Fontana et al. excluded patients with osteoarthritis higher than grade $2^{\circ}[15]$ since several authors reported that osteoarthritis may be a parameter to predict inferior results after hip arthroscopy in FAI patients [2, 34]. We excluded patients with corresponding cartilage defects "kissing lesions" as the results in the knee joint have been unsatisfying. This is in line with the finding of Fontana et al., who reported the worst results in patients with corresponding cartilage defects in the hip [15]. Schroeder et al. also excluded patients with radiographic signs of dysplasia. 
Table 3. Comparison of the NOVOCART ${ }^{\circledR}$ Inject and Chondrosphere.

\begin{tabular}{ll}
\hline NOVOCART ${ }^{\circledR}$ Inject & Chondrosphere $^{\circledR}$ \\
\hline $\begin{array}{l}\text { Cultivation within 3-4 weeks with pooled serum, BMP-2 and } \\
\text { insulin }\end{array}$ & Cultivation within 6-7 weeks in 200 mL autologous serum \\
$\begin{array}{l}\text { Injectable through a deformable needle } \\
\begin{array}{l}\text { Polymerized within 2 min after application through polyethylene } \\
\text { glycol crosslinking }\end{array}\end{array}$ & $\begin{array}{l}\text { Injectable through a deformable applicator } \\
\text { Bonding of chondrospheres after approximately 20 min }\end{array}$ \\
$\begin{array}{l}\text { Characterized autologous chondrocytes and in situ polymerizing } \\
\text { albumin-hyaluronic acid gel, phenotypic stability, positive } \\
\text { biologic effects (Inhibition of alkaline phosphatase, } \\
\text { vascularization, neurotrophic factors) }\end{array}$ & $\begin{array}{c}\text { Complete autologous cell product, phenotypic stability, produces } \\
\text { cartilage-specific matrix by induction of three-dimensional cell- } \\
\text { cell contacts, biocompatibility }\end{array}$ \\
$\begin{array}{l}\text { RCT at the knee running, studies with evidence level III at the } \\
\text { knee }\end{array}$ & $\begin{array}{c}\text { RCT at the knee running, multiple evidence level II and III studies } \\
\text { at the hip, knee and ankle }\end{array}$ \\
\hline
\end{tabular}

Patients with radiographic signs of osteoarthritis $\geq 1^{\circ}$ according to Kellgren and Lawrence were also excluded [17]. Körsmeier et al. in comparison does not specify exclusion criteria [16]. An overview of the current literature is displayed in Table 4.

In the present study with an average defect size of $2.21 \mathrm{~cm}^{2}$, we could also show a significant overall improvement in all scores at 16 months follow-up. We could not see inferior outcomes in correlation to larger defect sizes at 12 and 24 months after treatment, but this has to be interpreted carefully because of the small size of the study group.

Unfortunately, we are not able to comment on the quality of repair tissue or the defect filling after MACI as magnetic resonance imaging (MRI) or second-look surgery with histological or histomorphological analysis was not performed in this study.

There are two studies that performed second-look surgery. Körsmeier et al. performed second-look arthroscopy in two patients due to unsatisfactory range of motion 5 and 8 months after chondrosphere ${ }^{\circledR}$ implantation [16]. They describe a good ingrowth of the transplanted chondrocytes, but further histological examinations have not been performed. Fontana et al. performed one second-look arthroscopy in a patient who underwent AMIC 13 months previously. Here, a satisfactory tissue quality with the fibrocartilage-like aspect was observed. Unfortunately, no ACI patient had second-look arthroscopy [33]. However, in our opinion functional outcome is more important than imaging studies as a patient with satisfying outcome results but poor MRI scoring would not be advised to have revision surgery.

The results discussed above are not directly comparable, as different outcome scores have been used. Among others, Körsmeier et al. used the WOMAC score, which is only validated for patients with osteoarthritis [16]. Fontana et al. only used the mHHS/HHS, which is limited to pain, movement and daily activities $[15,33]$. These conventional scores do not reflect the expectations and aims of the mainly young and active patients with FAI. This demonstrates the limitation of the mHHS, which has been published previously [35]. Similar to Schroeder et al. [17] the iHOT33 was used in our study, which has been developed and validated especially for FAI patients to evaluate patient's symptoms, functional and sports limitation as well as social, emotional and occupational limitations [36]. Furthermore, we correlated the functional outcome results with the general health of the patient (EQ-5D) to evaluate possible influences on the results [25].

Several studies have reported on the importance of the integrity of the labral seal and superior results of labral repair in comparison to a partial excision [4, 37-39]. Therefore, it seems to be important to preserve the labrum to sustain its function as a seal and therefore its positive effects on the joint lubrication and protection of the cartilage surfaces [38]. Out of 29 patients 26 showed labral tears. In 23 of $26(88 \%)$ patients, a labral repair was performed. In three patients $(12 \%)$, the labral tear could not be repaired due to the severity of the tear. In the present study, no influence of the size of the labral tear could be seen in regard to the postoperative outcome.

\section{Complications}

In this study as well as in the current literature severe adverse events were not observed. Most complications are due to nerve affections like neuropraxia of the nervus pudendus or hypoesthesia of the forefoot because of traction. Only Körsmeier described reductions of the range of motion in two cases, reductions of the range of motion, which could possibly be related to the implantation surgery. We did not have re-operations or conversions to THA within the 19-month follow-up.

\section{Limitations}

There are several limitations. First of all, the present study only displays a small number of patients with a possible selection bias as mainly FAI patients were included. Unfortunately, there is no control group; hence, care should be taken when drawing conclusions. Only a short-term assessment of 19 months was done. We did not perform second-look arthroscopies or postoperative MRI scans in order to be able to comment on the defect filling. Additionally, no histomorphological analysis of cartilage biopsies was done. Therefore, we are not able to comment on the quality of the cartilage repair. 
Table 4. Summary of the current literature after treatment of hip cartilage defects with ACI/MACI.

\begin{tabular}{|c|c|c|c|c|c|c|c|c|c|c|}
\hline Author & Design & Procedure & $\begin{array}{c}\text { Patients } \\
\text { (male/female) }\end{array}$ & $\begin{array}{l}\text { Mean age } \\
\text { (range) }\end{array}$ & $\begin{array}{l}\text { Follow-up } \\
\text { (months) }\end{array}$ & $\begin{array}{c}\text { Score } \\
\text { improvement } \\
\text { (pre-post) }\end{array}$ & $\begin{array}{c}\text { Defect } \\
\text { size }\left(\mathrm{cm}^{2}\right)\end{array}$ & Localisation & Grade & $\begin{array}{l}\text { Additional } \\
\text { treatment }\end{array}$ \\
\hline $\begin{array}{l}\text { Fontana } \\
\text { et al. } \\
{[15]}\end{array}$ & $\begin{array}{l}\text { Retrospective } \\
\text { study }\end{array}$ & $\begin{array}{l}\text { ACI, polymer-based } \\
\text { scaffold BioSeed-C } \\
\text { (BioTissue } \\
\text { Technologies } \mathrm{GmbH} \text { ) }\end{array}$ & $15(9 / 6)$ & $40.7(22-52)$ & $73.8(72-76)$ & HHS 39.4 & 2.6 & $\begin{array}{l}\mathrm{A}(n=15) \\
\mathrm{FH}(n=3)\end{array}$ & $\begin{array}{l}\text { Outerbridge } \\
3-4\end{array}$ & Not mentioned \\
\hline $\begin{array}{l}\text { Fickert } \\
\text { et al. } \\
\text { [14] }\end{array}$ & Case series & $\begin{array}{l}\text { MACI, Chondrosphere } \\
\quad\left(\text { CO.DON }^{\circledR}\right)\end{array}$ & $6(5 / 1)$ & $33(25-45)$ & 11.2 & $\begin{array}{l}\text { mHHS } 23.5 \\
\text { NAHS } 28.1\end{array}$ & 3.6 & $\begin{array}{c}\mathrm{A}(n=5) \\
\mathrm{FH}(n=1)\end{array}$ & ICRS IIIa-IIb & LR 3 LPR 2 \\
\hline $\begin{array}{l}\text { Körsmeier } \\
\text { et al. } \\
\text { [16] }\end{array}$ & Case series & $\begin{array}{l}\text { MACI, Chondrosphere } \\
\left(\text { CO.DON }^{\circledR}\right)\end{array}$ & $16(14 / 2)$ & $31.8(20-47)$ & $16.1(10-29)$ & $\begin{array}{c}\text { NAHS } 26 \\
\text { WOMAC } 33\end{array}$ & 4.5 & $\mathrm{~A}(n=16)$ & $\begin{array}{l}\text { Outerbridge } \\
\quad 3-4\end{array}$ & LR 2 LPR 4 \\
\hline $\begin{array}{l}\text { Schroeder } \\
\text { et al. } \\
\text { [17] }\end{array}$ & Case series & $\begin{array}{l}\text { MACI, Chondrosphere } \\
\quad\left(\text { CO.DON }^{\circledR}\right)\end{array}$ & $20(16 / 4)$ & $33(22-49)$ & $12.1(6-24)$ & $\begin{array}{c}\text { mHHS } 30 \\
\text { iHOT33 35\% } \\
\text { SHV } 22 \%\end{array}$ & 5.1 & $\mathrm{~A}(n=20)$ & $\begin{array}{l}\text { Full-thickness } \\
\text { defects }\end{array}$ & LR 18 \\
\hline $\begin{array}{l}\text { Fontana } \\
\text { and } \\
\text { de Girolamo } \\
{[33]}\end{array}$ & Case series & $\begin{array}{l}\text { ACI, polymer-based } \\
\text { scaffold BioSeed }{ }^{\circledR}-\mathrm{C} \\
\text { (BioTissue } \\
\text { technologies GmbH) } \\
\text { vs. AMIC } \\
\text { Chondro-Gide }{ }^{\circledR}, \\
\text { (Geistlich Pharma } \\
\text { AG, Switzerland) }\end{array}$ & $\begin{array}{l}\text { ACT } 26 \\
(12 / 14) \\
\text { AMIC } 31 \\
(13 / 18)\end{array}$ & $\begin{array}{c}\text { ACT } \\
36 \pm 9.3 \\
\text { AMIC } \\
36.4 \pm 10.3\end{array}$ & 60 & $\begin{array}{c}\text { ACT mHHS } \\
37.8 \pm 5.9 \\
\text { AMIC mHHS } \\
39.1 \pm 5.9\end{array}$ & $\begin{array}{c}\text { ACT } \\
2.8 \pm 0.7 \\
\text { AMIC } \\
2.9 \pm 0.8\end{array}$ & $\begin{array}{l}\text { ACT A } \\
(n=26) \\
\text { AMIC A } \\
(n=31)\end{array}$ & $\begin{array}{l}\text { Outerbridge } \\
\quad 3-4\end{array}$ & Not mentioned \\
\hline
\end{tabular}

$\mathrm{LR}=$ Labrum repair, $\mathrm{LPR}=$ partial resection Labrum, $\mathrm{A}=$ Acetabulum, $\mathrm{FH}=$ Femoral Head. 


\section{Conclusion}

In this study, we present short-term data of new arthroscopic injectable matrix-associated, autologous chondrocyte implants as a treatment option for full-thickness cartilage defects of the hip. All patient-administered assessment scores demonstrated an increase in activity level, quality of life and reduction of pain after a 19-month follow-up. Further randomized controlled trails (RCTs) with comparison of natural history, bone marrow stimulation techniques and MACI of the hip have to confirm the results in long-term follow-up.

\section{Conflict of interest}

The authors declare no conflict of interest in relation with this paper.

\section{Funding}

The authors received no financial support for the research and/or authorship of this article.

\section{References}

1. Beck M et al. (2005) Hip morphology influences the pattern of damage to the acetabular cartilage: femoroacetabular impingement as a cause of early osteoarthritis of the hip. J Bone Joint Surg Br 87(7), 1012-1018.

2. Byrd JW, Jones KS (2010) Prospective analysis of hip arthroscopy with 10-year followup. Clin Orthop Relat Res 468(3), 741-746.

3. Haviv B et al. (2010) Arthroscopic femoral osteochondroplasty for cam lesions with isolated acetabular chondral damage. J Bone Joint Surg Br 92(5), 629-633.

4. Philippon MJ et al. (2009) Outcomes following hip arthroscopy for femoroacetabular impingement with associated chondrolabral dysfunction: minimum two-year follow-up. J Bone Joint Surg Br 91(1), 16-23.

5. Streich NA et al. (2009) Prognostic value of chondral defects on the outcome after arthroscopic treatment of acetabular labral tears. Knee Surg Sports Traumatol Arthrosc 17(10), 12571263.

6. Pearle AD, Warren RF, Rodeo SA (2005) Basic science of articular cartilage and osteoarthritis. Clin Sports Med 24(1), $1-12$.

7. Morlock M et al. (2001) Duration and frequency of every day activities in total hip patients. J Biomech 34(7), 873-881.

8. Fickert $\mathrm{S}$ et al. (2012) One-year clinical and radiological results of a prospective, investigator-initiated trial examining a novel, purely autologous 3-dimensional autologous chondrocyte transplantation product in the knee. Cartilage 3(1), 27-42.

9. Domb BG et al. (2015) Microfracture in the hip: results of a matched-cohort controlled study with 2-year follow-up. Am J Sports Med 43(8), 1865-1874.

10. Philippon MJ et al. (2008) Can microfracture produce repair tissue in acetabular chondral defects? Arthroscopy 24(1), $46-50$.
11. Singh PJ, O'Donnell JM (2010) The outcome of hip arthroscopy in Australian football league players: a review of 27 hips. Arthroscopy 26(6), 743-749.

12. Stafford GH, Bunn JR, Villar RN (2011) Arthroscopic repair of delaminated acetabular articular cartilage using fibrin adhesive. Results at one to three years. Hip Int 21(6), 744-750.

13. Domb BG et al. (2015) A matched-pair controlled study of microfracture of the hip with average 2-year follow-up: do fullthickness chondral defects portend an inferior prognosis in hip arthroscopy? Arthroscopy 31(4), 628-634.

14. Fickert S et al. (2014) Feasibility of arthroscopic 3-dimensional, purely autologous chondrocyte transplantation for chondral defects of the hip: a case series. Arch Orthop Trauma Surg 134(7), 971-978.

15. Fontana A et al. (2012) Arthroscopic treatment of hip chondral defects: autologous chondrocyte transplantation versus simple debridement - a pilot study. Arthroscopy 28(3), 322-329.

16. Körsmeier $\mathrm{K}$ et al. (2016) Arthroscopic three-dimensional autologous chondrocyte transplantation using spheroids for the treatment of full-thickness cartilage defects of the hip joint. Knee Surg Sports Traumatol Arthrosc 24(6), 2032-2037.

17. Schroeder JH et al. (2016) Injectable autologous chondrocyte transplantation for full thickness acetabular cartilage defects: early clinical results. Arch Orthop Trauma Surg 136(10), $1445-1451$.

18. Schutte J et al. (2010) A method for patterned in situ biofunctionalization in injection-molded microfluidic devices. Lab Chip 10(19), 2551-2558.

19. Scholz B et al. (2010) Suppression of adverse angiogenesis in an albumin-based hydrogel for articular cartilage and intervertebral disc regeneration. Eur Cell Mater 20, 24-36; discussion 36-7.

20. Anderer U, Libera J (2002) In vitro engineering of human autogenous cartilage. J Bone Miner Res 17(8), 1420-1429.

21. Meyer DC et al. (2006) Comparison of six radiographic projections to assess femoral head/neck asphericity. Clin Orthop Relat Res 445, 181-185.

22. Anderson LA et al. (2009) Acetabular cartilage delamination in femoroacetabular impingement. Risk factors and magnetic resonance imaging diagnosis. J Bone Joint Surg Am 91(2), 305-313.

23. Baumann F et al. (2016) Validation of a German version of the International Hip Outcome Tool 12 (iHOT12) according to the COSMIN checklist. Health Qual Life Outcomes 14, 3.

24. Christensen CP et al. (2003) The nonarthritic hip score: reliable and validated. Clin Orthop Relat Res 406, 75-83.

25. EuroQol G (1990) EuroQol - a new facility for the measurement of health-related quality of life. Health Policy 16(3), 199-208.

26. Schubert T et al. (2009) Long-term effects of chondrospheres on cartilage lesions in an autologous chondrocyte implantation model as investigated in the SCID mouse model. Int J Mol Med 23(4), 455-460.

27. McCarthy JC et al. (2011) What factors influence long-term survivorship after hip arthroscopy? Clin Orthop Relat Res 469(2), 362-371.

28. Farjo LA, Glick JM, Sampson TG (1999) Hip arthroscopy for acetabular labral tears. Arthroscopy 15(2), 132-137.

29. Mockel G, Labs K (2014) Complications in hip arthroscopy and follow-up therapy. Analysis over a 5 -year time period with a total of 13,000 cases. Orthopade 43(1), 6-15. 
30. Niethammer TR et al. (2016) Analysis of the autologous chondrocyte quality of matrix-based autologous chondrocyte implantation in the knee joint. Int Orthop 40(1), 205-212.

31. Benz K et al. (2013) Maintenance of "stem cell" features of cartilage cell sub-populations during in vitro propagation. J Transl Med 11, 27.

32. Mancini D, Fontana A (2014) Five-year results of arthroscopic techniques for the treatment of acetabular chondral lesions in femoroacetabular impingement. Int Orthop 38(10), 2057-2064.

33. Fontana A, de Girolamo L (2015) Sustained five-year benefit of autologous matrix-induced chondrogenesis for femoral acetabular impingement-induced chondral lesions compared with microfracture treatment. Bone Joint J 97-B(5), 628-635.

34. Domb BG, Gui C, Lodhia P (2015) How much arthritis is too much for hip arthroscopy: a systematic review. Arthroscopy $31(3), 520-529$.
35. Aprato A, Jayasekera N, Villar RN (2012) Does the modified Harris hip score reflect patient satisfaction after hip arthroscopy? Am J Sports Med 40(11), 2557-2560.

36. Baumann F et al. (2016) Validation of a German version of the International Hip Outcome Tool (G-iHOT33) according to the COSMIN checklist: how much improvement is clinically relevant? Arch Orthop Trauma Surg 136(1), 83-91.

37. Espinosa $\mathrm{N}$ et al. (2006) Treatment of femoro-acetabular impingement: preliminary results of labral refixation. J Bone Joint Surg Am 88(5), 925-935.

38. Ferguson SJ et al. (2003) An in vitro investigation of the acetabular labral seal in hip joint mechanics. J Biomech 36(2), 171-178.

39. Larson CM, Giveans MR, Stone RM (2012) Arthroscopic debridement versus refixation of the acetabular labrum associated with femoroacetabular impingement: mean 3.5-year follow-up. Am J Sports Med 40(5), 1015-1021.

Cite this article as: Thier S, Weiss C \& Fickert S (2017) Arthroscopic autologous chondrocyte implantation in the hip for the treatment of full-thickness cartilage defects. SICOT J, 3, 72 